\title{
Sunlight exposure and cardiovascular risk factors in the REGARDS study: a cross-sectional split-sample analysis
}

\author{
Shia T Kent ${ }^{1}$, Mary Cushman², George Howard ${ }^{3}$, Suzanne E Judd ${ }^{3}$, William L Crosson ${ }^{4}$, Mohammad Z Al-Hamdan ${ }^{4}$
} and Leslie A McClure ${ }^{3 *}$

\begin{abstract}
Background: Previous research has suggested that vitamin D and sunlight are related to cardiovascular outcomes, but associations between sunlight and risk factors have not been investigated. We examined whether increased sunlight exposure was related to improved cardiovascular risk factor status.

Methods: Residential histories merged with satellite, ground monitor, and model reanalysis data were used to determine previous-year sunlight radiation exposure for 17,773 black and white participants aged $45+$ from the US. Exploratory and confirmatory analyses were performed by randomly dividing the sample into halves. Logistic regression models were used to examine relationships with cardiovascular risk factors.

Results: The lowest, compared to the highest quartile of insolation exposure was associated with lower high-density lipoprotein levels in adjusted exploratory $(-2.7 \mathrm{mg} / \mathrm{dL}[95 \%$ confidence interval: $-4.2,-1.2])$ and confirmatory $(-1.5 \mathrm{mg} / \mathrm{dL}$ [95\% confidence interval: $-3.0,-0.1])$ models. The lowest, compared to the highest quartile of insolation exposure was associated with higher systolic blood pressure levels in unadjusted exploratory and confirmatory, as well as the adjusted exploratory model $(2.3 \mathrm{mmHg}$ [95\% confidence interval: $0.8,3.8]$ ), but not the adjusted confirmatory model (1.6 $\mathrm{mg} / \mathrm{dL}$ [95\% confidence interval: $-0.5,3.7]$ ).

Conclusions: The results of this study suggest that lower long-term sunlight exposure has an association with lower high-density lipoprotein levels. However, all associations were weak, thus it is not known if insolation may affect cardiovascular outcomes through these risk factors.
\end{abstract}

Keywords: Sunlight, Temperature, Weather, Climate, Environment, Blood pressure, Lipids and lipoproteins

\section{Background}

Cardiovascular health varies with season, weather, and climate [1-3]. While seasonal temperature variation has been a primary target of investigation, sunlight also varies seasonally and has not been adequately investigated. Sunlight directly alters vitamin D status, but aside from skin cancer there are few data on how sunlight directly affects human health [4-6]. Although there are few studies of vitamin $\mathrm{D}$ and stroke, there is indication that vitamin $\mathrm{D}$ insufficiency may increase vascular event risk factors $[4,5,7]$. Both geographic latitude and vitamin D level have

\footnotetext{
* Correspondence: Imcclure@uab.edu

${ }^{3}$ Department of Biostatistics, 1665 University Blvd, University of Alabama at Birmingham, Birmingham 35294, Alabama

Full list of author information is available at the end of the article
}

been linked to blood pressure, with potential mechanisms involving the renin-angiotensin system, inflammation, vasculature, or glycemic control $[8,9]$. Exposure to ultraviolet $\mathrm{B}$ radiation has also been shown to affect blood pressure and other stroke risk factors $[7,8,10]$. Vitamin D and cholesterol have a common upstream metabolite 7-dehydrocholesterol, which is converted to previtamin $\mathrm{D}_{3}$ in the skin after exposure to sunlight [11]. Observational studies have shown that higher vitamin $\mathrm{D}$ blood levels may improve lipid levels [12]. Higher vitamin D levels may also improve health status of those with chronic kidney disease, although the results are mixed [13]. Inflammation is related to stroke, blood pressure, lipid levels, and kidney function, and may also be related to vitamin D levels [14-16]. There are seasonal variations 
in inflammation, although this could be due to infection and allergy $[16,17]$. Vitamin D may also improve kidney function by acting as renin-angiotensin system inhibitors [18] and improving microalbuminuria [19].

Sunlight radiation and temperature are available from the North American Land Data Assimilation System Phase 2 (NLDAS-2) forcing. These data were matched to an individual's geocoded home residence and have previously been used in the REasons for Geographic And Racial Differences in Stroke (REGARDS) study, finding that reduced sunlight exposure was associated with increased stroke incidence [20]. In this manuscript, we examine whether increased residential sunlight exposure is related to increased blood pressure, serum lipid levels, kidney function, and inflammation. Since both skin color and the kidney are linked with vitamin D production and regulation [21,22], and since Vitamin D levels have been posited to contribute to racial health disparities [23], we examine whether increased sunlight radiation exposure leads to poorer outcomes among black participants and those with impaired kidney function. To account for the multiple hypotheses we are testing, we perform a split-sample replication analysis. The large size of the REGARDS cohort allows us to split the participants into two samples: a hypothesis-generating sample to explore possible significant relationships, and a confirmatory sample to independently assess the associations found in the exploratory analyses, reducing the likelihood of Type I error. We hypothesize that increased sunlight exposure is related to improved cardiovascular risk factor status in both exploratory and confirmatory samples of the REGARDS study.

\section{Methods}

\section{Study participants}

REGARDS is a longitudinal study of United States (US) participants aged 45 years and older [24]. The REGARDS study was designed to investigate reasons underlying the higher rate of stroke mortality among blacks, compared with non-Hispanic whites, and among residents in the Southeastern United States, compared with other US regions. At baseline, 56\% of the participants were residing in the stroke belt (an area of the US with high stroke mortality in the Southeast including GA, NC, SC, AL, TN, LA, AR, MS), with the remaining $44 \%$ from the rest of the contiguous 48 US. Participants from the stroke buckle (an even higher stroke mortality region comprised of the coastal plains of $\mathrm{NC}, \mathrm{SC}$, and GA) comprised $21 \%$ of the REGARDS population. The cohort population at baseline was $42 \%$ African-American/58\% white and $45 \%$ male $/ 55 \%$ female. Further details on the study are available elsewhere [24]. The REGARDS study and the current analysis were approved by the Institutional Review Boards of participating institutions.

\section{Data collection}

At baseline, a telephone interview was conducted during which informed consent was obtained and the participant's self-reported demographic and behavioral factors, and medical history were recorded. Participants were then visited in their homes by a trained health professional who collected blood pressure, height, weight, blood, urine, and conducted electrocardiograms (ECGs), and obtained written informed consent. Blood and urine were sent to a central repository at the University of Vermont and ECG data were read at Wake Forest University. The examiner also left a residential history form to fill and mail.

\section{Assessment of sunlight exposure and temperature}

We used data from the National Aeronautics and Space Administration (NASA) - National Oceanic and Atmospheric Administration (NOAA) NLDAS-2 dataset to determine sunlight radiation and temperature. The NLDAS-2 dataset is based on model reanalysis data and remotely-sensed and ground observations, and consists of a grid surface with $\sim 14 \mathrm{~km}$ resolution over North America [25]. NLDAS-2 solar radiation that was assessed at one-hour intervals was used to calculate a daily total referred to herein as daily "insolation" [26]. For this study, we merged daily insolation and maximum air temperatures with data from REGARDS' residential history form, which consists of locations where the participant had lived prior to enrollment into REGARDS, along with age when relocating. Each location the participant recorded was matched to a feature in the US Geological Survey's Geographic Names Information System using ArcGIS 9.3. For participants who had a period of missing residential data, due to having an unidentifiable location or residence outside of the contiguous 48 United States, we used only the existing residential history to compute environmental exposure averages. We assumed participants moved during July of the indicated moving year.

As in our previous studies, we calculated each month's average daily insolation and temperature exposure at each participant's residential location to estimate each participant's average exposure for the year previous to baseline [20,27]. We then categorized insolation and temperature exposure into quartiles. In order to capture extreme exposures, we also categorized insolation and temperature exposure using cutpoints at the $5^{\text {th }}$ and $95^{\text {th }}$ percentiles.

\section{Outcomes}

Blood pressure was measured during the REGARDS inhome visit by a trained technician using a standard protocol and regularly tested aneroid sphygmomanometer and was calculated as an average of two measurements taken after the participant was seated for five minutes. Hypertension 
was defined as present with self-reported use of antihypertensive medications, systolic blood pressure $(\mathrm{SBP}) \geq 140$ $\mathrm{mm} \mathrm{Hg}$, or a diastolic blood pressure (DBP) $\geq 90 \mathrm{~mm} \mathrm{Hg}$. Blood was collected during the in-home visit, and shipped to the central laboratory at the University of Vermont using standard protocols. Standard assays were used to determine lipid levels and high-sensitivity C-reactive protein (CRP) assays were used to determine the level of CRP, which was log transformed due to a skewed distribution. CRP levels were categorized into low/medium risk (CRP $\leq 3 \mathrm{mg} / \mathrm{dL}$ ) and high risk (CRP $>3 \mathrm{mg} / \mathrm{dL})$. Dyslipidemia was defined as present with self-reported use of lipid-lowering medication, total cholesterol $\geq 240 \mathrm{mg} / \mathrm{dL}$, low-density lipoprotein (LDL) $\geq 160 \mathrm{mg} / \mathrm{dL}$, or high-density lipoprotein (HDL) $\leq$ $40 \mathrm{mg} / \mathrm{dL}$. Kidney function was determined by the estimated glomerular filtration rate (eGFR) computed using the CKD EPI equation (participants with eGFR $<60$ classified as having impaired kidney function) [28].

\section{Statistical methods}

Because some confounders had missing data for large numbers of participants, we attempted to minimize selection bias by creating a separate "missing" category for any variable that had $>1,000$ participants missing data. Participants were excluded due to data anomalies, stroke or coronary heart disease at baseline, missing residential history, and missing confounder data (for those will $<1,000$ participants missing data). Of the 30,239 participants enrolled at baseline, 17,773 participants were available for analyses (Figure 1).

To perform a split-sample replication analysis we randomly assigned the eligible participants into one of two samples of equal size. In the first "exploratory" sample, we ran multivariable logistic or linear regression models adjusting for temperature, age, race, region (stroke belt, stroke buckle, or non-stroke belt), gender, education (less than high school, high school graduate, some college, or college graduate), income $(<\$ 20,000, \$ 20,000$ to $\$ 34,999, \$ 35,000$ to $\$ 74,999$, or $\geq \$ 75,000)$, quartiles of vitamin $\mathrm{D}$ intake, exercise (none, 1 to 3 times/week, or $\geq 3$ times/week), alcohol use (none, moderate: $\leq 1$ drink per day for women or $\leq 2$ drinks per day for men, or heavy: > 1 drink per day for women and $>2$ drinks per day for men), smoking status (current, past, or never) and body mass index $(<18.5,18.5$ to $24.9,25$ to 29.9 , or $\geq 30$ ). We also adjusted for statin use in models with cholesterol, HDL, or LDL as the outcome, and adjusted for antihypertensive medication use in the models with SBP as the outcome. Using interaction terms in fully adjusted models, we tested for multiplicative interactions between insolation and each of race or impaired kidney function on our outcome variables. In the second "confirmatory" sample, we re-ran all models for outcomes with significant associations in the explanatory sample.

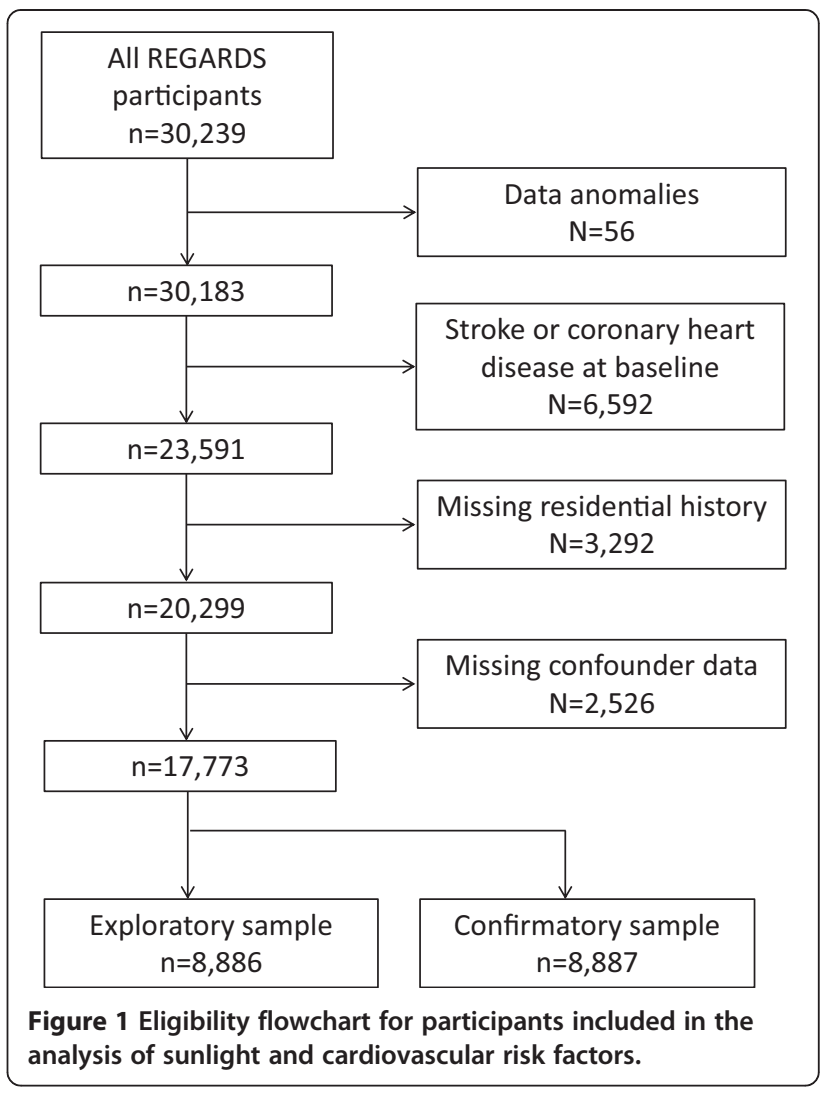

This study was approved by Institutional Review Boards of participating institutions.

\section{Results}

\section{Exploratory and confirmatory samples}

The exploratory $(n=8886)$ and confirmatory $(n=8887)$ samples did not significantly differ by most variables (Table 1; Additional file 1: Table S1). The exception is that the confirmatory sample had a higher proportion of males, although the difference in proportions was only $2.1 \%$ $(\mathrm{p}=0.0041)$.

\section{Systolic blood pressure}

Exploratory analyses found monotonic associations between quartiles of insolation; the lowest, compared to the highest quartile of insolation exposure was associated with 3.5 and $2.3 \mathrm{mmHg}$ higher SBP for unadjusted and fully adjusted models, respectively (Table 2). Confirmatory models replicated this association in the unadjusted model, but the adjusted confirmatory model was not significant. In exploratory analyses insolation significantly interacted with race (Table 3); blacks had stronger associations in both unadjusted and adjusted exploratory models. Blacks, compared to whites, also had a stronger association between insolation and SBP in the confirmatory unadjusted model, but not in the confirmatory adjusted 
Table 1 Meteorological and secondary stroke endpoint distributions by insolation exposure in the exploration ( $\mathrm{n}=\mathbf{8 8 8 6}$ ) and confirmatory $(n=8887)$ samples

\begin{tabular}{|c|c|c|c|}
\hline Characteristic & Exploratory sample & Confirmatory sample & P-value \\
\hline \multicolumn{4}{|l|}{ Quartiles of insolation, n (\%) } \\
\hline 1st (12327 to $15565 \mathrm{KJ} / \mathrm{m} 2 /$ day $)$ & $2207(24.8 \%)$ & $2236(25.2 \%)$ & \\
\hline 2nd (15565 to $16724 \mathrm{KJ} / \mathrm{m} 2 /$ day) & $2180(24.5 \%)$ & $2263(25.5 \%)$ & 0.22 \\
\hline 3rd (16724 to $17724 \mathrm{KJ} / \mathrm{m} 2 /$ day) & $2223(25.0 \%)$ & $2220(25.0 \%)$ & \\
\hline 4th (17724 to $22733 \mathrm{KJ} / \mathrm{m} 2 /$ day) & $2276(25.6 \%)$ & $2168(24.4 \%)$ & \\
\hline \multicolumn{4}{|l|}{ Maximum Temperature, n (\%) } \\
\hline 1st quartile ( 8.5 to $17.8^{\circ} \mathrm{C}$ ) & $2206(24.8 \%)$ & $2237(25.2 \%)$ & \\
\hline 2nd quartile (17.8 to $\left.21.7^{\circ} \mathrm{C}\right)$ & $2247(25.3 \%)$ & $2198(24.7 \%)$ & 0.82 \\
\hline 3rd quartile (21.7 to $\left.24.0^{\circ} \mathrm{C}\right)$ & $2224(25.0 \%)$ & $2217(24.9 \%)$ & \\
\hline 4th quartile (24.0 to $31.7^{\circ} \mathrm{C}$ ) & $2209(24.9 \%)$ & $2235(25.1 \%)$ & \\
\hline SBP, mean mmHg (SD) & $126.5(16.4)$ & $126.4(16.0)$ & 0.49 \\
\hline Cholesterol, mean mg/dL (SD) & $195.0(38.2)$ & $194.3(37.8)$ & 0.25 \\
\hline $\mathrm{LDL}$, mean mg/dL (SD) & $116.8(34.0)$ & $116.3(33.9)$ & 0.34 \\
\hline $\mathrm{HDL}$, mean mg/dL (SD) & $53.3(16.3)$ & $53.2(16.1)$ & 0.24 \\
\hline Ln CRP, mean mg/dL (SD) & $0.77(1.16)$ & $0.75(1.18)$ & 0.17 \\
\hline Hypertensive, n (\%) & $4847(54.5 \%)$ & $4760(53.6 \%)$ & 0.19 \\
\hline Dyslipidemia, n (\%) & $4778(53.8 \%)$ & $4718(53.1 \%)$ & 0.36 \\
\hline High CRP risk category, n (\%) & $3511(39.5 \%)$ & $3449(38.8 \%)$ & 0.3377 \\
\hline Impaired kidney function, n (\%) & $737(8.3 \%)$ & $722(8.1 \%)$ & 0.68 \\
\hline
\end{tabular}

$\mathrm{n}=$ Number; SD = standard deviation; SBP = Systolic Blood Pressure; LDL = Low-Density Lipoprotein; HDL = High-Density Lipoprotein; CRP = C-reactive protein .

P-values for categorical variables were determined by likelihood-ratio chi-square tests and for continuous variables by ANOVA F-test.

model. After removing temperatures from the fully adjusted confirmatory model, insolation was significant and parameter estimates had similar magnitudes to the unadjusted confirmatory model. Insolation exposure $<5^{\text {th }}$ versus $\geq 5^{\text {th }}$ percentile was significantly associated with 2.4 and $2.5 \mathrm{mmHg}$ higher SBP in exploratory unadjusted and adjusted models, respectively. However, these associations were not significant in confirmatory analyses.

\section{Total cholesterol, LDL, and HDL}

Insolation did not have significant associations with total cholesterol or LDL in exploratory models (Table 2). Lower quartiles of insolation exposure were significantly associated with lower HDL levels in all analyses. The lowest, compared to the highest quartile of insolation exposure was significantly associated with 1.3 and $1.5 \mathrm{mg} / \mathrm{dL}$ lower HDL levels in adjusted exploratory and confirmatory models, respectively. Insolation exposure $<5^{\text {th }}$ versus $\geq 5^{\text {th }}$ percentile was associated with lower HDL levels in the adjusted exploratory, but not adjusted confirmatory model. Insolation exposure $<95^{\text {th }}$ versus $\geq 95^{\text {th }}$ percentile was associated with $2.7 \mathrm{mg} / \mathrm{dL}$ lower HDL levels in the adjusted exploratory model, but this association was not significant in the confirmatory model.

\section{Continuous C-reactive protein}

Quartiles of insolation, and insolation exposure $<5^{\text {th }}$ versus $\geq 5^{\text {th }}$ percentile were each significantly associated with differences in CRP levels in unadjusted exploratory and confirmatory models, but these associations were no longer significant after adjustment. Insolation exposure $<95^{\text {th }}$ versus $\geq 95^{\text {th }}$ percentile was not associated with a difference in CRP levels in any models (Table 2).

\section{Hypertension}

Insolation was not significantly associated with hypertension in any analyses (Table 4).

\section{Dyslipidemia}

Insolation was not significantly associated with dyslipidemia in any main effect models (Table 4). In exploratory models, insolation exposure $<5^{\text {th }}$ versus $\geq 5^{\text {th }}$ percentile was associated with an increased risk of dyslipidemia among those without impaired kidney function, but associated with a decreased risk of dyslipidemia among those without impaired kidney function (Additional file 2: Table S2). However, this was not replicated in confirmatory models.

\section{High levels of C-reactive protein}

Quartiles of insolation exposure were significantly associated with high CRP in the unadjusted exploratory model 
Table 2 Differences in continuous secondary cardiovascular endpoints associated with residential insolation exposure in exploratory and confirmatory analyses

\begin{tabular}{|c|c|c|c|c|c|}
\hline Insolation exposure & SBP $(\mathrm{mmHg})$ & Total cholesterol (mg/dL) & LDL (mg/dL) & HDL (mg/dL) & LnCRP (mg/dL) \\
\hline \multicolumn{6}{|l|}{ Quartiles of insolation exposure } \\
\hline \multicolumn{6}{|l|}{ Exploratory analyses - Unadjusted } \\
\hline $1^{\text {st }}$ vs $4^{\text {th }}$ quartile & $3.5(2.6,4.5)$ & $1.5(-0.7,3.8)$ & $2.4(0.5,4.4)$ & $-1.3(-2.2,-0.3)$ & $0.0(-0.1,0.0)$ \\
\hline $2^{\text {nd }}$ vs $4^{\text {th }}$ quartile & $2.3(1.4,3.3)$ & $0.3(-1.9,2.6)$ & $0.8(-1.2,2.8)$ & $-2.0(-2.9,-1.0)$ & $0.1(0.0,0.1)$ \\
\hline $3^{\text {rd }}$ vs $4^{\text {th }}$ quartile & $1.9(0.9,2.9)$ & $0.2(-2.0,2.5)$ & $0.4(-1.6,2.3)$ & $-0.9(-1.8,0.1)$ & $0.1(0.0,0.2)$ \\
\hline \multicolumn{6}{|l|}{ Exploratory analyses - Fully adjusted } \\
\hline $1^{\text {st }}$ vs $4^{\text {th }}$ quartile & $2.3(0.8,3.8)$ & $-3.1(-6.6,0.4)$ & $-1.1(-4.2,2.0)$ & $-2.7(-4.2,-1.2)$ & $0.0(-0.1,0.1)$ \\
\hline $2^{\text {nd }}$ vs $4^{\text {th }}$ quartile & $1.9(0.8,3.1)$ & $-2.1(-4.8,0.7)$ & $-0.7(-3.1,1.7)$ & $-2.0(-3.2,-0.9)$ & $0.1(0.0,0.2)$ \\
\hline $3^{\text {rd }}$ vs $4^{\text {th }}$ quartile & $1.4(0.4,2.4)$ & $-0.8(-3.1,1.5)$ & $-0.5(-2.6,1.6)$ & $-0.6(-1.6,0.3)$ & $0.1(0.0,0.1)$ \\
\hline \multicolumn{6}{|l|}{ Confirmatory analyses - Unadjusted } \\
\hline $1^{\text {st }}$ vs $4^{\text {th }}$ quartile & $3.3(2.3,4.2)$ & N/A & N/A & $-0.2(-1.1,0.8)$ & $-0.1(-0.1,0.0)$ \\
\hline $2^{\text {nd }}$ vs $4^{\text {th }}$ quartile & $1.7(0.8,2.6)$ & N/A & N/A & $-1.8(-2.8,-0.9)$ & $0.0(-0.1,0.1)$ \\
\hline $3^{\text {rd }}$ vs $4^{\text {th }}$ quartile & $1.8(0.9,2.6)$ & N/A & N/A & $-0.6(-1.6,0.3)$ & $0.1(0.0,0.2)$ \\
\hline \multicolumn{6}{|l|}{ Confirmatory analyses - Fully adjusted } \\
\hline $1^{\text {st }}$ vs $4^{\text {th }}$ quartile & $1.6(-0.5,3.7)$ & N/A & N/A & $-1.5(-3.0,-0.1)$ & $0.0(-0.1,0.1)$ \\
\hline $2^{\text {nd }}$ vs $4^{\text {th }}$ quartile & $1.1(-0.5,2.7)$ & N/A & N/A & $-2.1(-3.2,-0.9)$ & $0.0(-0.1,0.1)$ \\
\hline $3^{\text {rd }}$ vs $4^{\text {th }}$ quartile & $1.4(-1.0,1.7)$ & N/A & N/A & $-0.5(-1.4,0.6)$ & $0.0(0.0,0.1)$ \\
\hline \multicolumn{6}{|l|}{ Low insolation exposure } \\
\hline \multicolumn{6}{|l|}{$<5^{\text {th }}$ vs $\geq 5^{\text {th }}$ percentile } \\
\hline Exploratory analyses - Unadjusted & $2.4(0.8,3.9)$ & $0.5(-3.1,4.1)$ & $1.3(-2.0,4.5)$ & $-1.0(-2.6,0.5)$ & $-0.2(-0.3,-0.1)$ \\
\hline Exploratory analyses - Fully adjusted & $2.5(1.0,4.1)$ & $-0.4(-4.1,3.3)$ & $0.9(-2.4,4.2)$ & $-1.7(-3.2,-0.1)$ & $-0.1(-0.2,0.0)$ \\
\hline Confirmatory analyses - Unadjusted & $1.1(-0.4,2.7)$ & N/A & N/A & $-0.1(-1.6,1.5)$ & $-0.1(-0.2,0.0)$ \\
\hline Confirmatory analyses - Fully adjusted & $0.6(-1.7,2.9)$ & N/A & N/A & $0.0(-1.7,1.6)$ & $-0.1(-0.2,0.0)$ \\
\hline \multicolumn{6}{|l|}{ High insolation exposure } \\
\hline \multicolumn{6}{|l|}{$<95^{\text {th }}$ vs $\geq 95^{\text {th }}$ percentile } \\
\hline Exploratory analyses - Unadjusted & $0.3(-1.3,1.9)$ & $-1.9(-5.5,1.8)$ & $0.4(-2.8,3.6)$ & $-3.6(-5.1,-2.0)$ & $0.0(-0.1,0.1)$ \\
\hline Exploratory analyses - Fully adjusted & $0.2(-1.4,1.7)$ & $-2.7(-6.3,1.0)$ & $0.0(-3.2,3.2)$ & $-2.7(-4.2,-1.2)$ & $-0.1(-0.2,0.0)$ \\
\hline Confirmatory analyses - Unadjusted & N/A & N/A & N/A & $-1.7(-3.3,-0.2)$ & N/A \\
\hline Confirmatory analyses - Fully adjusted & N/A & N/A & N/A & $-1.5(-3.1,0.0)$ & N/A \\
\hline
\end{tabular}

SBP = Systolic Blood Pressure; LDL = Low-Density Lipoprotein; HDL = High-Density Lipoprotein; CRP = C-reactive protein.

Numbers in parentheses are $95 \%$ confidence intervals. Numbers in bold are significant $(p<0.05)$.

All fully adjusted models are adjusted for temperature, age, race, region, gender, education, income, vitamin D intake, alcohol use, smoking, and body mass index. SBP models are further adjusted for antihypertensive medication use. Total cholesterol, LDL, and HDL models are further adjusted for statin use. Models with insolation categorized into quartiles, and using cutoffs at the $5^{\text {th }}$ and $95^{\text {th }}$ percentiles were adjusted for temperature exposures into quartiles and using cutoffs at the $5^{\text {th }}$ and $95^{\text {th }}$ percentiles, respectively.

(Table 4). However, this association was not monotonic. In the unadjusted exploratory, insolation exposure $<5^{\text {th }}$ versus $\geq 5^{\text {th }}$ percentile was significantly associated with high CRP. In unadjusted exploratory models, quartiles of insolation exposure significantly interacted with kidney impairment and insolation exposure $<5^{\text {th }}$ vs $\geq 5^{\text {th }}$ percentile significantly interacted with race (Additional file 3: Tables S3 and Additional file 4: Table S4). However, no insolation main effects or interaction terms in exploratory adjusted models or in any of the confirmatory models were significant.

\section{Kidney impairment}

Insolation was not significantly associated with kidney impairment in any analyses (Table 4).

\section{Discussion}

This analysis adds to the limited previous research addressing the relationship between sunlight and vascular health. Higher myocardial infarction, stroke, and adverse vascular risk factor rates have been reported in farther northern latitudes, but it is not clear whether this is due to environmental, social, or other factors $[4,29,30]$. There is also some evidence of higher myocardial infarction and stroke rates during the winter $[1,31]$ although other research contradicts this [3]. While lower temperatures have been shown to be associated with high blood pressures $[2,32]$, there may also be seasonal variations in lipid levels that are independent of temperature [33]. Sunlight exposure is another seasonal factor, and might affect vascular 
Table 3 Differences in systolic blood pressure (SBP) associated with residential insolation exposure in exploratory and confirmatory analyses, by race

\begin{tabular}{|c|c|c|c|}
\hline \multirow[t]{2}{*}{ Quartiles of insolation exposure } & \multicolumn{3}{|c|}{ SBP $(\mathrm{mmHg})$} \\
\hline & Blacks & Whites & p-value \\
\hline \multicolumn{4}{|l|}{ Exploratory analyses - Unadjusted } \\
\hline $1^{\text {st }}$ vs $4^{\text {th }}$ quartile & $4.7(3.2,6.1)$ & $2.4(1.1,3.6)$ & \\
\hline $2^{\text {nd }}$ vs $4^{\text {th }}$ quartile & $1.4(-0.1,3.0)$ & $3.1(1.9,4.3)$ & 0.0005 \\
\hline $3^{\text {rd }}$ vs $4^{\text {th }}$ quartile & $1.3(-0.2,2.8)$ & $2.1(0.9,3.3)$ & \\
\hline \multicolumn{4}{|l|}{ Exploratory analyses - Fully adjusted } \\
\hline $1^{\text {st }}$ vs $4^{\text {th }}$ quartile & $3.8(2.8,5.6)$ & $1.4(-0.2,3.1)$ & \\
\hline $2^{\text {nd }}$ vs $4^{\text {th }}$ quartile & $1.1(-0.5,2.7)$ & $2.4(1.0,3.8)$ & 0.0012 \\
\hline $3^{\text {rd }}$ vs $4^{\text {th }}$ quartile & $1.2(-0.2,2.7)$ & $1.5(0.2,2.7)$ & \\
\hline \multicolumn{4}{|l|}{ Confirmatory analyses - Unadjusted } \\
\hline $1^{\text {st }}$ vs $4^{\text {th }}$ quartile & $4.6(3.2,6.1)$ & $1.9(0.7,3.1)$ & \\
\hline $2^{\text {nd }}$ vs $4^{\text {th }}$ quartile & $1.8(0.2,3.3)$ & $1.9(0.7,3.0)$ & 0.0058 \\
\hline $3^{\text {rd }}$ vs $4^{\text {th }}$ quartile & $1.7(0.2,3.2)$ & $1.7(0.5,2.9)$ & \\
\hline \multicolumn{4}{|c|}{ Confirmatory analyses - Fully adjusted } \\
\hline $1^{\text {st }}$ vs $4^{\text {th }}$ quartile & $1.7(-0.7,4.1)$ & $1.6(-0.9,4.1)$ & \\
\hline $2^{\text {nd }}$ vs $4^{\text {th }}$ quartile & $0.6(-1.5,2.6)$ & $1.6(-0.4,3.7)$ & 0.5855 \\
\hline $3^{\text {rd }}$ vs $4^{\text {th }}$ quartile & $-0.3(-2.3,1.6)$ & $1.0(-0.8,2.8)$ & \\
\hline
\end{tabular}

Numbers in parentheses are $95 \%$ confidence intervals. Numbers in bold are significant $(p<0.05)$.

All fully adjusted models are adjusted for temperature, age, race, region, gender, education, income, vitamin D intake, alcohol use, smoking, body mass index, and antihypertensive medication use. Models with insolation categorized into quartiles, and using cutoffs at the $5^{\text {th }}$ and $95^{\text {th }}$ percentiles were adjusted for temperature exposures into quartiles and using cutoffs at the $5^{\text {th }}$ and $95^{\text {th }}$ percentiles, respectively.

risk factors through vitamin D metabolism, which is increasingly found to be related to various chronic diseases. There is indication that vitamin D insufficiency may increase vascular event risk [34,35] and adversely impact various vascular risk factors [8]. For most people, vitamin $\mathrm{D}$ status is primarily determined by sunlight exposure $[6,36]$. Blood serum 25(OH)D levels are usually used to determine vitamin $\mathrm{D}$ status and can fluctuate with differential exposure to light and dietary intake.

This study is the third using REGARDS data merged with NASA meteorological data that demonstrated a possible link between sunlight and health [20,27]. The results of this study suggest that lower long-term sunlight exposure has an association with lower HDL levels, after accounting for confounders. Since this association was found in both exploratory and confirmatory models, it is not likely that this finding is due to chance. However, the magnitude of this association is small, since those in the lowest, compared to the highest quartile of insolation exposure had only about $2 \mathrm{mg} / \mathrm{dL}$ lower HDL levels compared to those with higher sunlight exposures. In addition, while observational studies have shown that higher HDL levels are associated with lower cardiovascular risk, interventional studies have not been consistent and are ongoing, so the clinical significance of this association is unknown [37]. Sunlight also had significant univariate relationships with SBP in both exploratory and confirmatory models, but this association did not remain significant after confounder adjustment in the confirmatory models. In addition, the associations with SBP were also small, with adjusted effect sizes less than $3 \mathrm{mmHg}$. We also found that the association between insolation and SBP may be stronger among blacks than whites, but this interaction was also not significant in adjusted confirmatory models. We determined that this was due to the inclusion of temperatures in the model. Previous research in REGARDS and other studies have found lower temperatures to be related to higher blood pressures [38]. It is not clear why the inclusion of temperature would eliminate the significant association between insolation and SBP in the exploratory, but not confirmatory analyses. Collinearity may be an issue, with higher maximum temperatures correlated with higher insolation levels. These results agree with our previous analyses which suggest that decreased sunlight exposure is related to increased stroke incidence and increased likelihood of cognitive impairment and decline [20,27,39], although given the effect sizes it is unlikely that the traditional risk factors explored fully mediate these associations.

There is little other research examining sunlight and vascular risk, but a recent Hong Kong study found that temperature and air pressure, but not solar radiation, were significantly associated with stroke [40]. Our current and previous research differs from this study in many ways, including temporality (exposure within days of outcome, rather than one year exposure in this analysis), location (a small tropical area rather than a wide range of 
Table 4 Hazard ratios for continuous secondary cardiovascular endpoints associated with residential insolation exposure in exploratory and confirmatory analyses

\begin{tabular}{|c|c|c|c|c|}
\hline Insolation exposure & Hypertension & Dyslipidemia & High CRP & Impaired kidney \\
\hline \multicolumn{5}{|l|}{ Quartiles of insolation exposure } \\
\hline \multicolumn{5}{|l|}{ Exploratory analyses - Unadjusted } \\
\hline $1^{\text {st }}$ vs $4^{\text {th }}$ quartile & $1.1(0.9,1.2)$ & $1.0(0.9,1.1)$ & $0.9(0.8,1.1)$ & $0.8(0.7,1.0)$ \\
\hline $2^{\text {nd }}$ vs $4^{\text {th }}$ quartile & $1.0(0.9,1.2)$ & $1.1(1.0,1.2)$ & $1.1(0.9,1.2)$ & $0.9(0.8,1.2)$ \\
\hline $3^{\text {rd }}$ vs $4^{\text {th }}$ quartile & $1.2(1.0(1.3)$ & $1.0(0.9,1.2)$ & $1.2(1.0,1.3)$ & $0.9(0.7,1.1)$ \\
\hline \multicolumn{5}{|l|}{ Exploratory analyses - Fully adjusted } \\
\hline $1^{\text {st }}$ vs $4^{\text {th }}$ quartile & $1.2(0.9,1.4)$ & $0.9(0.8,1.1)$ & $1.1(0.9,1.3)$ & $0.8(0.6,1.2)$ \\
\hline $2^{\text {nd }}$ vs $4^{\text {th }}$ quartile & $1.0(0.9,1.2)$ & $1.0(0.9,1.2)$ & $1.2(1.0,1.4)$ & $0.9(0.7,1.2)$ \\
\hline $3^{\text {rd }}$ vs $4^{\text {th }}$ quartile & $1.1(0.9,1.2)$ & $1.0(0.9,1.1)$ & $1.1(1.0,1.3)$ & $0.9(0.7,1.2)$ \\
\hline \multicolumn{5}{|l|}{ Confirmatory analyses - Unadjusted } \\
\hline $1^{\text {st }}$ vs $4^{\text {th }}$ quartile & $\mathrm{N} / \mathrm{A}$ & N/A & $1.0(0.8,1.1)$ & $\mathrm{N} / \mathrm{A}$ \\
\hline $2^{\text {nd }}$ vs $4^{\text {th }}$ quartile & N/A & N/A & $1.0(0.9,1.1)$ & N/A \\
\hline $3^{\text {rd }}$ vs $4^{\text {th }}$ quartile & $\mathrm{N} / \mathrm{A}$ & $\mathrm{N} / \mathrm{A}$ & $1.1(1.0,1.2)$ & N/A \\
\hline \multicolumn{5}{|l|}{ Confirmatory analyses - Fully adjusted } \\
\hline $1^{\text {st }}$ vs $4^{\text {th }}$ quartile & N/A & N/A & $1.1(0.9,1.4)$ & N/A \\
\hline $2^{\text {nd }}$ vs $4^{\text {th }}$ quartile & $\mathrm{N} / \mathrm{A}$ & N/A & $1.0(0.8,1.2)$ & $\mathrm{N} / \mathrm{A}$ \\
\hline $3^{\text {rd }}$ vs $4^{\text {th }}$ quartile & N/A & N/A & $1.0(0.9,1.2)$ & N/A \\
\hline \multicolumn{5}{|l|}{ Low insolation exposure } \\
\hline \multicolumn{5}{|l|}{$<5^{\text {th }}$ vs $\geq 5^{\text {th }}$ percentile } \\
\hline Exploratory analyses - Unadjusted & $1.0(0.8,1.2)$ & $1.1(0.9,1.3)$ & $0.8(0.6,0.9)$ & $0.8(0.6,1.2)$ \\
\hline Exploratory analyses - Fully adjusted & $1.2(1.0,1.5)$ & $1.2(1.0,1.5)$ & $0.9(0.7,1.1)$ & $0.8(0.6,1.3)$ \\
\hline Confirmatory analyses - Unadjusted & $\mathrm{N} / \mathrm{A}$ & $\mathrm{N} / \mathrm{A}$ & $0.9(0.7,1.1)$ & $\mathrm{N} / \mathrm{A}$ \\
\hline Confirmatory analyses - Fully adjusted & N/A & N/A & $0.9(0.7,1.2)$ & $\mathrm{N} / \mathrm{A}$ \\
\hline \multicolumn{5}{|l|}{ High insolation exposure } \\
\hline \multicolumn{5}{|l|}{$<95^{\text {th }}$ vs $\geq 95^{\text {th }}$ percentile } \\
\hline Exploratory analyses - Unadjusted & $1.0(0.8,1.2)$ & $1.2(1.0,1.5)$ & $1.0(0.9,1.3)$ & $0.8(0.6,1.1)$ \\
\hline Exploratory analyses - Fully adjusted & $0.9(0.8,1.2)$ & $1.2(0.9,1.4)$ & $0.9(0.7,1.1)$ & $0.8(0.6,1.2)$ \\
\hline Confirmatory analyses - Unadjusted & $\mathrm{N} / \mathrm{A}$ & N/A & N/A & $\mathrm{N} / \mathrm{A}$ \\
\hline Confirmatory analyses - Fully adjusted & N/A & N/A & N/A & N/A \\
\hline
\end{tabular}

CRP $=$ C-reactive protein.

Numbers in parentheses are $95 \%$ confidence intervals. Numbers in bold are significant $(p<0.05)$.

Fully adjusted models are adjusted for temperature, age, race, region, gender, education, income, vitamin D intake, alcohol use, smoking, and body mass index. Models with insolation categorized into quartiles, and using cutoffs at the $5^{\text {th }}$ and $95^{\text {th }}$ percentiles were adjusted for temperature exposures into quartiles and using cutoffs at the $5^{\text {th }}$ and $95^{\text {th }}$ percentiles, respectively.

mostly temperate areas), and that our study did not include air pressure. Since 25(OH)D3 has a biological half-life of several weeks [34], it would be plausible that our longer term sunlight exposure would have a larger effect on vitamin D levels, and thus on vascular risk. And while we did not include air pressure in our models, we did account for temperature, as this is the primary meteorological variable that has been shown to have associations with vascular risk.

Exposure misclassification exists as a possible source of bias. This could happen if during the time period of an exposure measurement a participant spent a large amount of time in a climate different from that indicated by the outdoor exposures linked to his or her residence.
In addition to exposure misclassification, it is possible that our findings are confounded by spatial autocorrelation, although that is not likely since adding region to the model did not attenuate the relationship. Another potential limitation is that there may be confounders for which we have not accounted, such as air pollution. While we did not correct for variables such as cloudiness and altitude, insolation measures represent the sunlight energy received on the ground, so the effects of such variables do not need to be included.

\section{Conclusions}

This study found a relationship between sunlight exposure and HDL levels that is not likely due to chance. However, 
all observed associations were of small magnitudes. More research is needed to determine whether insolation affects cardiovascular outcomes through these risk factors.

\section{Additional files}

Additional file 1: Table S1. Confounder distributions in exploration ( $n=8886)$ and confirmatory $(n=8887)$ samples; Provides a table of REGARDS participant baseline characteristics in the exploratory and confirmatory samples.

Additional file 2: Table S2. Hazard ratios (95\% confidence intervals) for dyslipidemia associated with residential insolation exposure in exploratory and confirmatory analyses, by kidney impairment; Provides a table examining the interaction between low insolation exposure and kidney impairment on dyslipidemia.

Additional file 3: Table S3. Hazard ratios (95\% confidence intervals) for high C-reactive protein associated with residential insolation exposure in exploratory and confirmatory analyses, by kidney impairment; Provides a table examining the interaction between quartiles of insolation exposure and kidney impairment on high CRP.

Additional file 4: Table S4. Hazard ratios (95\% confidence intervals) for high C-reactive protein associated with residential insolation exposure in exploratory and confirmatory analyses, by race; Provides a table examining the interaction between low insolation exposure and race on high CRP.

\section{Abbreviations}

CRP: C-reactive protein; DBP: Diastolic blood pressure;

ECG: Electrocardiogram; eGFR: Estimated glomerular filtration rate; HDL: High-density lipoprotein; LDL: High-density lipoprotein; NOAA: National Oceanic and Atmospheric Administration; NLDAS-2: North American Land Data Assimilation System Phase 2; REGARDS: REasons for Geographic and Racial Differences; SBP: Systolic blood pressure.

\section{Competing interests}

The authors declare that they have no competing interest.

\section{Authors' contributions}

STK helped originate the hypothesis, managed the data, performed the analyses, and drafted the manuscript. MC provided medical, physiological, and epidemiological expertise. GH provided epidemiological expertise and contributed to the study design. SEJ provided physiological and epidemiological expertise. WLC managed the data and provided meteorological expertise. MZA managed the data. LAM helped originate the manuscript hypothesis, provided statistical expertise, and contributed to the study design. All authors helped to edit the manuscript, and have read and approved the final manuscript.

\section{Acknolwedgements}

The authors thank the other investigators, the staff, and the participants of the REGARDS study for their valuable contributions. A full list of participating REGARDS investigators and institutions can be found at http://www.regardsstudy.org.

The NLDAS hourly data used in this study were acquired as part of the mission of NASA's Earth Science Division and archived and distributed by the Goddard Earth Sciences (GES) Data and Information Services Center (DISC). This work was supported by the National Institute of Neurological Disorders and Stoke [U01 NS041588]; and the National Aeronautics and Space Administration [grant\# NNX09AV81G].

\section{Author details}

'Department of Epidemiology, 1665 University Blvd, University of Alabama at Birmingham, Birmingham 35294, Alabama. Department of Medicine, University of Vermont College of Medicine, Burlington, VT 05405, Canada. ${ }^{3}$ Department of Biostatistics, 1665 University Blvd, University of Alabama at Birmingham, Birmingham 35294, Alabama. ${ }^{4}$ National Space Science and Technology Center, NASA Marshall Space Flight Center, 320 Sparkman Drive, Huntsville 35805, Alabama.
Received: 16 October 2013 Accepted: 13 June 2014

Published: 19 June 2014

\section{References}

1. Wang Y, Levi CR, Attia JR, D'Este CA, Spratt N, Fisher J: Seasonal variation in stroke in the Hunter Region, Australia: a 5-year hospital-based study, 1995-2000. Stroke 2003, 34(5):1144-1150.

2. Alperovitch A, Lacombe JM, Hanon O, Dartigues JF, Ritchie K, Ducimetiere P, Tzourio C: Relationship between blood pressure and outdoor temperature in a large sample of elderly individuals: the three-city study. Arch Intern Med 2009, 169(1):75-80.

3. Sobel E, Zhang ZX, Alter M, Lai SM, Davanipour Z, Friday G, McCoy R, Isack $T$, Levitt L: Stroke in the Lehigh Valley: seasonal variation in incidence rates. Stroke 1987, 18(1):38-42.

4. Wong A: Incident solar radiation and coronary heart disease mortality rates in Europe. Eur J Epidemio/ 2008, 23(9):609-614.

5. Turner PL, Mainster MA: Circadian photoreception: ageing and the eye's important role in systemic health. Br J Ophthalmol 2008, 92(11):1439-1444.

6. Reusch J, Ackermann H, Badenhoop K: Cyclic changes of vitamin D and PTH are primarily regulated by solar radiation: 5-year analysis of a German (50 degrees N) population. Horm Metab Res 2009, 41(5):402-407.

7. Rosen CJ: Clinical practice: vitamin D insufficiency. N Engl J Med 2011, 364(3):248-254.

8. Judd SE, Tangpricha V: Vitamin D deficiency and risk for cardiovascular disease. Am J Med Sci 2009, 338(1):40-44.

9. Al Mheid I, Patel RS, Tangpricha V, Quyyumi AA: Vitamin D and cardiovascular disease: is the evidence solid? Eur Heart J 2013, 34(48):3691-3698.

10. Krause R, Buhring M, Hopfenmuller W, Holick MF, Sharma AM: Ultraviolet B and blood pressure. Lancet 1998, 352(9129):709-710.

11. Cutillas-Marco E, Prosper AF, Grant WB, Morales-Suarez-Varela MM: Vitamin $D$ status and hypercholesterolemia in Spanish general population. Dermatoendocrinol 2013, 5(3):358-362.

12. Alam U, Najam O, Al-Himdani S, Benoliel S, Jinadev P, Berry JL, Kew M, Asghar O, Petropoulos IN, Malik RA: Marked vitamin D deficiency in patients with diabetes in the UK: ethnic and seasonal differences and an association with dyslipidaemia. Diabet Med 2012, 29(10):1343-1345.

13. Kandula P, Dobre M, Schold JD, Schreiber MJ Jr, Mehrotra R, Navaneethan SD: Vitamin D supplementation in chronic kidney disease: a systematic review and meta-analysis of observational studies and randomized controlled trials. Clin J Am Soc Nephrol 2011, 6(1):50-62.

14. Hopkins MH, Owen J, Ahearn TU, Fedirko V, Flanders WD, Jones DP, Bostick RM: Effects of supplemental vitamin D and calcium on biomarkers of inflammation in colorectal adenoma patients: a randomized, controlled clinical trial. Cancer Prev Res (Phila) 2011, 4(10):1645-1654

15. Petchey WG, Johnson DW, Isbel NM: Shining D' light on chronic kidney disease: mechanisms that may underpin the cardiovascular benefit of vitamin D. Nephrology (Carlton) 2011, 16(4):351-367.

16. Thorand B, Zierer A, Huth C, Linseisen J, Meisinger C, Roden M, Peters A, Koenig W, Herder C: Effect of serum 25-hydroxyvitamin D on risk for type 2 diabetes may be partially mediated by subclinical inflammation: results from the MONICA/KORA Augsburg study. Diabetes Care 2011, 34(10):2320-2322

17. Kampe M, Stalenheim G, Janson C, Stolt I, Carlson M: Systemic and local eosinophil inflammation during the birch pollen season in allergic patients with predominant rhinitis or asthma. Clin Mol Allergy 2007, 5:4.

18. Brown JM, Secinaro K, Williams JS, Vaidya A: Evaluating hormonal mechanisms of vitamin $D$ receptor agonist therapy in diabetic kidney disease: the VALIDATE-D study. BMC Endocr Disord 2013, 13(1):33.

19. Huang Y, Yu H, Lu J, Guo K, Zhang L, Bao Y, Chen H, Jia W: Oral supplementation with cholecalciferol $800 \mathrm{IU}$ ameliorates albuminuria in Chinese type 2 diabetic patients with nephropathy. PLoS One 2012, 7(11):e50510.

20. Kent ST, McClure LA, Judd SE, Howard VJ, Crosson WL, Al-Hamdan MZ, Wadley VG, Peace F, Kabagambe EK: Short- and long-term sunlight radiation and stroke incidence. Ann Neurol 2013, 73(1):32-37.

21. Chen TC, Chimeh F, Lu Z, Mathieu J, Person KS, Zhang A, Kohn N, Martinello S, Berkowitz R, Holick MF: Factors that influence the cutaneous synthesis and dietary sources of vitamin D. Arch Biochem Biophys 2007, 460(2):213-217. 
22. Cuppari L, Garcia Lopes MG, Kamimura MA: Vitamin D biology: from the discovery to its significance in chronic kidney disease. J Ren Nutr 2011, 21(1):113-116.

23. Williams S, Malatesta K, Norris K: Vitamin D and chronic kidney disease. Ethn Dis 2009, 19(4 Suppl 5):S5-S8. 11

24. Howard VJ, Cushman M, Pulley L, Gomez CR, Go RC, Prineas RJ, Graham A, Moy CS, Howard G: The reasons for geographic and racial differences in stroke study: objectives and design. Neuroepidemiology 2005, 25(3):135-143.

25. Cosgrove B, Lohmann D, Mitchell K, Houser P, Wood E, Schaake J, Robock A, Marshall C, Sheffield J, Duan Q, Luo L, Higgins RW, Pinker RT, Tarpley JD, Meng J: Real-time and retrospective forcing in the North American land data assimilation system (NLDAS) project. J Geophys Res 2003, 108(D22):8842-8854.

26. Al-Hamdan MZ, Crosson WL, Economou SA, Estes MG, Estes SM, Hemmings SJ, Kent ST, Puckett M, Quattrochi DA, Rickman DL, Wade GM, McClure LA: Environmental public health applications using remotely sensed data. Geocarto Int 2014, 29(1):85-98.

27. Kent ST, Kabagambe EK, Wadley VG, Howard VJ, Crosson WL, Al-Hamdan $M Z$, Judd SE, Peace F, McClure LA: The relationship between long-term sunlight radiation and cognitive decline in the REGARDS cohort study. Int J Biometeorol 2014, 58(3):361-370.

28. Levey AS, Stevens LA, Schmid CH, Zhang YL, Castro AF 3rd, Feldman HI, Kusek JW, Eggers P, Van Lente F, Greene T, Coresh J, CKD-EPI (Chronic Kidney Disease Epidemiology Collaboration): A new equation to estimate glomerular filtration rate. Ann Intern Med 2009, 150(9):604-612.

29. Peter I, Otremski I, Livshits G: Geographic variation in vascular mortality in Eurasia: spatial autocorrelation analysis of mortality variables and risk factors. Ann Hum Biol 1996, 23(6):471-490.

30. Feelisch M, Kolb-Bachofen V, Liu D, Lundberg JO, Revelo LP, Suschek CV, Weller RB: Is sunlight good for our heart? Eur Heart J 2010, 31(9):1041-1045

31. Manfredini R, Fabbian F, Pala M, Tiseo R, De Giorgi A, Manfredini F, Malagoni AM, Signani F, Andreati C, Boari B, Salmi R, Imberti D, Gallerani M: Seasonal and weekly patterns of occurrence of acute cardiovascular diseases: does a gender difference exist? J Womens Health (Larchmt) 2011, 20(11):1663-1668.

32. Medina-Ramon M, Zanobetti A, Cavanagh DP, Schwartz J: Extreme temperatures and mortality: assessing effect modification by personal characteristics and specific cause of death in a multi-city case-only analysis. Environ Health Perspect 2006, 114(9):1331-1336.

33. Tung P, Wiviott SD, Cannon CP, Murphy SA, McCabe CH, Gibson CM: Seasonal variation in lipids in patients following acute coronary syndrome on fixed doses of pravastatin $(40 \mathrm{mg})$ or atorvastatin $(80 \mathrm{mg})$ (from the pravastatin or atorvastatin evaluation and infection therapy-thrombolysis in myocardial infarction 22 [PROVE IT-TIMI 22] study). Am J Cardiol 2009, 103(8):1056-1060.

34. Wang TJ, Pencina MJ, Booth SL, Jacques PF, Ingelsson E, Lanier K, Benjamin EJ, D'Agostino RB, Wolf M, Vasan RS: Vitamin D deficiency and risk of cardiovascular disease. Circulation 2008, 117(4):503-511.

35. Pilz S, Dobnig H, Fischer JE, Wellnitz B, Seelhorst U, Boehm BO, Marz W: Low vitamin $d$ levels predict stroke in patients referred to coronary angiography. Stroke 2008, 39(9):2611-2613.

36. Webb AR: Who, what, where and when-influences on cutaneous vitamin D synthesis. Prog Biophys Mol Biol 2006, 92(1):17-25.

37. Aim-High Investigators: The role of niacin in raising high-density lipoprotein cholesterol to reduce cardiovascular events in patients with atherosclerotic cardiovascular disease and optimally treated low-density lipoprotein cholesterol: baseline characteristics of study participants: the atherothrombosis intervention in metabolic syndrome with low HDL/ high triglycerides: impact on global health outcomes (AIM-HIGH) trial. Am Heart J 2011, 161(3):538-543.

38. Kent ST, Howard G, Prineas RJ, Crosson WL, McClure LA: The association of remotely-sensed outdoor temperature with blood pressure levels in REGARDS: a cross-sectional study of a large, national cohort of African-American and white participants. Environ Health 2011, 10(1):7.
39. Kent ST, McClure LA, Crosson WL, Arnett DK, Wadley VG, Sathiakumar N: Effect of sunlight exposure on cognitive function among depressed and non-depressed participants: a REGARDS cross-sectional study. Environ Health 2009, 8:34.

40. Goggins WB, Woo J, Ho S, Chan EY, Chau PH: Weather, season, and daily stroke admissions in Hong Kong. Int J Biometeorol 2012, 56(5):865-872.

doi:10.1186/1471-2377-14-133

Cite this article as: Kent et al: Sunlight exposure and cardiovascular risk factors in the REGARDS study: a cross-sectional split-sample analysis. BMC Neurology 2014 14:133.

\section{Submit your next manuscript to BioMed Central and take full advantage of:}

- Convenient online submission

- Thorough peer review

- No space constraints or color figure charges

- Immediate publication on acceptance

- Inclusion in PubMed, CAS, Scopus and Google Scholar

- Research which is freely available for redistribution

Submit your manuscript at www.biomedcentral.com/submit
C) Biomed Central 